\title{
L-Aspartic Acid Capped CdS Quantum Dots as a High Performance Fluorescence Assay for Sliver Ions (I) Detection
}

\author{
Zhezhe Wang ${ }^{1,2}$, Xuechun Xiao ${ }^{2, *}$, Yue Yang ${ }^{2}$, Tong Zou ${ }^{1}$, Xinxin Xing ${ }^{2}$, Rongjun Zhao ${ }^{1,2}$, \\ Zidong Wang ${ }^{1}$ and Yude Wang ${ }^{1,3, *}$ \\ 1 School of Materials Science and Engineering, Yunnan University, Kunming 650091, China \\ 2 Department of Physics, Yunnan University, Kunming 650091, China \\ 3 Key Lab of Quantum Information of Yunnan Province, Yunnan University, Kunming 650091, China \\ * Correspondence: xchxiao@ynu.edu.cn (X.X.); ydwang@ynu.edu.cn (Y.W.); \\ Tel.: +86-871-65930112 (X.X.); +86-871-65035570 (Y.W.); Fax: +86-871-65153832 (Y.W.)
}

Received: 29 June 2019; Accepted: 29 July 2019; Published: 14 August 2019

\begin{abstract}
A new high performance fluorescence assay for detection of $\mathrm{Ag}^{+}$based on $\mathrm{CdS}$ quantum dots (QDs) using L-Aspartic acid (L-Asp) as a stabilizer was proposed in this work. The CdS quantum dots conjugation with L-Aspartic acid (L-Asp@CdS QDs) were successfully synthesized via a simple hydrothermal process. The QDs have a fluorescence emission band maximum at $595 \mathrm{~nm}$ with a quantum yield of $11 \%$. The obtained CdS QDs exhibit a particle size of $1.63 \pm 0.28 \mathrm{~nm}$ and look like quantum dot flowers. Basically, the fluorescence intensity of L-Asp@CdS QDs can be enhanced only upon addition of $\mathrm{Ag}^{+}$and a redshift in the fluorescence spectrum was observed. Under optimum conditions, the fluorescence enhancement of L-Asp@CdS QDs appeared to exhibit a good linear relationship in between $100-7000 \mathrm{nM}\left(\mathrm{R}^{2}=0.9945\right)$ with the $\mathrm{Ag}^{+}$concentration, with a detection limit of $39 \mathrm{nM}$. The results indicated that the L-Asp@CdS QDs were well used in detection for $\mathrm{Ag}^{+}$as fluorescence probe in aqueous solution with high sensitivity and selectivity. Moreover, the sensing system has been applied in detection $\mathrm{Ag}^{+}$in real water samples. The recovery test results were $98.6 \% \sim 113 \%$, and relative standard deviation $(n=5)$ is less than $3.6 \%$, which was satisfactory.
\end{abstract}

Keywords: L-Aspartic acid; CdS quantum dots; fluorescence assay; $\mathrm{Ag}^{+}$detection; Fluorescence enhancement

\section{Introduction}

Semiconductor quantum dots (QDs) [1,2], whose size is less than the material Bohr exciton radius, have received more and more attention due to their size dependence and novel optical properties during the past decades. Their three-dimensions confined to the nanoscales with a size typically in the range of 1-10 nm [1,3]. Unlike bulk materials, they have unique optical and electronic properties including wide excitation spectra, narrow symmetric and tunable emission spectra. Contemporarily, fluorescent semiconductor quantum dots, have attracted much attention in bio-imaging [4], solar cells [5], light-emitting diodes [6] and sensing [7,8]. Moreover, they have high photobleaching thresholds and excellent photostability advantages compared with traditional organic fluorescent dye.

CdS QDs is typical representatives of IIB-VIA semiconductor QDs (e.g., CdS, CdSe, CdTe and $\mathrm{ZnS}$ ) [9]. However, the further applications of these semiconductor QDs in environmental detecting are limited by reason of their own toxicity. Therefore, organic molecules are selected as modifiers, which aim at reducing the surface defects and toxicity of semiconductor QDs. In recent years, surface functionalization and modification of QDs have widely applied as fluorescent probe in chemical and biological analysis [8-12]. So far, various organic ligands, such as thioglycolic acid [13], cysteamine [14] 
and 3-mercaptopropionic acid [8], citric acid [10] etc., have been applied in the quantum dots surface modification and functionalization. However, some modifiers are toxic, which do not comport with the green environmental protection science and technology philosophy. L-Aspartic acid (L-Asp), one of the essential amino acids in protein, is a naturally occurring amino acid without toxicity. Thus, CdS QDs surface-functionalized with L-Asp in water have been synthesized and characterized.

Currently, sliver is widely used in photographic materials, metallurgy, medicine, electroplating, etc. [15-19]. Trace amounts of $\mathrm{Ag}^{+}$will harmless to people, but the U.S. Environmental Protection Agency reports that $\mathrm{Ag}^{+}$could be harmful to fish and microorganisms when the concentration of $\mathrm{Ag}^{+}$ is higher than $1.6 \mathrm{nM}$ [20]. According to the World Health Organization (WHO), the limitation of $\mathrm{Ag}^{+}$ in drinking water is $0.05 \mathrm{mg} / \mathrm{L}(467 \mathrm{nM})$ [21]. As a result, selective detection of $\mathrm{Ag}^{+}$is important due to its severe pollution issue and potential toxicity. At present, the main method of monitoring the $\mathrm{Ag}^{+}$mainly include inductively coupled plasma-mass spectrometry (ICP-MS), electrochemical and flame atomic absorption spectrometry (FAAS) [22-24]. However, those traditional methods have some shortcomings, such as poor selectivity, low sensitivity, time-consuming and tedious process. Recently, fluorescence probe is being focused gradually for the detection of free $\mathrm{Ag}^{+}$, which surmounts the weakness of other methods.

In this work, we studied fluorescent turn-on assay of $\mathrm{Ag}^{+}$in aqueous solution based on L-Asp functionalized CdS QDs, which were synthesized by a facile hydrothermal method. It is found that the L-Asp@CdS QDs have a good selectivity to $\mathrm{Ag}^{+}$ions from a coexisting solution system containing other metal ions, such as $\mathrm{Al}^{3+}, \mathrm{Co}^{2+}, \mathrm{Cu}^{2+}, \mathrm{Fe}^{2+}, \mathrm{Fe}^{3+}, \mathrm{Hg}^{2+}, \mathrm{Na}^{+}, \mathrm{K}^{+}, \mathrm{La}^{3+}, \mathrm{Li}^{+}, \mathrm{Ni}^{2+}, \mathrm{Pb}^{2+}, \mathrm{Mn}^{2+}$, $\mathrm{Mg}^{2+}, \mathrm{Cd}^{2+}, \mathrm{Ca}^{2+}$ and $\mathrm{Zn}^{2+}$. Besides, the present fluorescent sensor system has been applied to the $\mathrm{Ag}^{+}$determination in real water samples and the results are agreeable.

\section{Materials and Methods}

\subsection{Materials}

Cadmium chloride hydrate $\left(\mathrm{CdCl}_{2} \cdot 2 \cdot 5 \mathrm{H}_{2} \mathrm{O}\right)$, thioacetamide (TAA), and sodium hydroxide $(\mathrm{NaOH})$ were obtained from Aladdin Chemistry Co. Ltd. (Shanghai, China). Trihydroxymethylaminomethane (Tris), hydrochloric acid and L-Aspartic acid (L-Asp) were provided by Shanghai Macklin Biochemical Co. Ltd. (Shanghai, China). All metal salts were purchased from Tianjin Zhiyuan Chemical Reagent Co. Ltd. (Tianjin, China). The reagents were used without further purification.

\subsection{Synthesis and Characterization of L-Asp@CdS QDs}

L-Aspartic acid capped CdS QDs were synthesized in aqueous solution using a simple method. $\mathrm{CdCl}_{2} \cdot 2.5 \mathrm{H}_{2} \mathrm{O}(0.195 \mathrm{~g}, 0.85 \mathrm{mmol})$ and L-Asp $(0.2714 \mathrm{~g}, 2.04 \mathrm{mmol})$ were mixed with $50 \mathrm{~mL}$ ultrapure water in beaker with magnetic stirring. Five minutes later, the $\mathrm{pH}$ of the solution was adjusted to 10 with $4 \mathrm{~mL}$ of $1 \mathrm{M}$ sodium hydroxide solution. Then, TAA $(0.032 \mathrm{~g}, 0.425 \mathrm{mmol})$ was added and the mixture was stirred vigorously to homogeneity. Subsequently, the mixture was moved into a $100 \mathrm{~mL}$ steel autoclave and retained at $100{ }^{\circ} \mathrm{C}$ for $30 \mathrm{~min}$. After being naturally cooled to room temperature, the obtained light yellow solution was removed to dialyze for $12 \mathrm{~h}$ with a $300 \mathrm{Da}$ dialysis bag.

The morphological and structure of L-Asp@CdS QDs were analyzed by X-ray diffraction (XRD, Rigaku TTRIII-18KW, Rigaku Corporation, Tokyo, Japan) with a Cu K $\alpha$ radiation $(\lambda=1.54056 \AA)$, transmission electron microscopy (TEM, 200 kV, JEOL, Tokyo, Japan), Renishaw inVia Raman microscope (Renishaw, London, UK), K-Alpha ${ }^{+}$system X-ray photoelectron spectroscopy (XPS, Thermo Fisher Scientific Company, Waltham, MA, USA), AVATAR360 FT-IR spectrophotometer and Seiko SPA-400 SPM atomic force microscope (AFM, JEOL, Tokyo, Japan). The optical properties of L-Asp@CdS QDs were acquired on the Horiba Fluorolog-3 spectrofluorometer (Horiba, NY, USA) and Jinghua Instruments UV-1800 spectrophotometer (Quantaurus-Tau, Hamamatsu, Japan). The pH of 
the current system was monitored by an inoLab pH Level 1 precision $\mathrm{pH}$ meter (Weilheim, Germany). The fluorescence quantum yield was computed by the following equation [10]:

$$
\mathrm{QY}_{(\text {sample })}=\left(F_{\text {sample }} / F_{\text {ref }}\right)\left(A_{\text {ref }} / A_{\text {sample }}\right)\left(\eta_{\text {sample }}^{2} / \eta_{\text {ref }}^{2}\right) \mathrm{QY}_{\text {ref }}
$$

Rhodamine 6G was selected as the reference standard and its solvent was ethanol (QY $=95 \%)$. $F, A$ and $\eta$ are the area under the emission spectra, the absorbance at the excitation wavelength and the refractive index of solvents, respectively.

\subsection{Detection of $\mathrm{Ag}^{+}$by L-Asp@CdS QDs}

Fluorescence enhancement of the L-Asp@CdS QDs by $\mathrm{Ag}^{+}$was carried out with a typical procedure. An amount of $250 \mu \mathrm{L}$ L-Asp@CdS QDs solution and $100 \mu \mathrm{L}$ various concentrations of $\mathrm{Ag}^{+}$were diluted with $4 \mathrm{~mL}$ of distilled water in $10 \mathrm{~mL}$ plastic centrifuge tube. Next, the plastic centrifuge tube was filled to $5 \mathrm{~mL}$ with $0.3 \mathrm{M}$ Tris-HCl buffered solution. The L-Asp@CdS QDs solution was diluted to $5 \mathrm{~mL}$ with ultrapure water. Finally, $\mathrm{Ag}^{+}$concentration was obtained on the range from $100 \mathrm{nM}$ to $10 \mu \mathrm{M}$. Relative fluorescence intensity $\left(\mathrm{F} / \mathrm{F}_{0}, \mathrm{~F}_{0}\right.$ and $\mathrm{F}$ are the fluorescence intensity of L-Asp@CdS QDs before and after addition of metal ions, respectively) was used to represent the fluorescence enhancement efficiency. These solutions were analyzed at $\lambda_{\mathrm{em}} / \lambda_{\mathrm{ex}}=595 / 405 \mathrm{~nm}$. To verify the feasibility of the fluorescence assay, drinking water from the Yunnan spring, Kunming City, was as the real water sample.

\subsection{Interference Studies}

The following procedure was demonstrated to study the selectivity of L-Asp@CdS QDs to $\mathrm{Ag}^{+}$. All metal salts were purchased from Kunming Maidesen: $\mathrm{KCl}, \mathrm{NaCl}, \mathrm{CdCl}_{2} \cdot 2.5 \mathrm{H}_{2} \mathrm{O}, \mathrm{BaCl}_{2} \cdot 2 \mathrm{H}_{2} \mathrm{O}$, $\mathrm{CaCl}_{2}, \mathrm{FeCl}_{3} \cdot 6 \mathrm{H}_{2} \mathrm{O}, \mathrm{CuCl}_{2} \cdot 2 \mathrm{H}_{2} \mathrm{O}, \mathrm{FeCl}_{2} \cdot 4 \mathrm{H}_{2} \mathrm{O}, \mathrm{AlCl}_{3} \cdot 6 \mathrm{H}_{2} \mathrm{O}, \mathrm{MnCl}_{2} \cdot 4 \mathrm{H}_{2} \mathrm{O}, \mathrm{NiCl}_{2} \cdot 6 \mathrm{H}_{2} \mathrm{O}, \mathrm{CoCl}_{2} \cdot 6 \mathrm{H}_{2} \mathrm{O}$, $\mathrm{ZnCl}_{2}, \mathrm{Mg}\left(\mathrm{NO}_{3}\right)_{2} \cdot 6 \mathrm{H}_{2} \mathrm{O}, \mathrm{Pb}\left(\mathrm{NO}_{3}\right)_{2}, \mathrm{LaCl}_{3} \cdot 7 \mathrm{H}_{2} \mathrm{O}, \mathrm{HgCl}_{2}$ and $\mathrm{LiNO}_{3}$. The stock solution of all metal ions $(2.5 \mathrm{mM})$ was prepared in ultrapure water, which were diluted to various concentrations were used in experimental testing. An amount of $250 \mu \mathrm{L}$ L-Asp@CdS QDs solution and $100 \mu \mathrm{L}$ a certain concentration interfering metal ions were diluted with $4 \mathrm{~mL}$ of distilled water in $10 \mathrm{~mL}$ plastic centrifuge tube. Next, the plastic centrifuge tube was filled to $5 \mathrm{~mL}$ with $0.3 \mathrm{M}$ Tris-HCl buffered solution. Then the concentrations of all interfering metal ions was $50 \mu \mathrm{M}$.

\section{Results and Discussion}

\subsection{Characterization of the L-Asp@CdS QDs}

Figure 1 shows the morphology and particle size of the as-synthesized L-Asp@CdS QDs. The TEM image (Figure 1a) and high-resolution TEM (HRTEM) image (Figure 1b) illustrate that the uniform quantum dot flowers (about $10 \mathrm{~nm}$ ) are composed of L-Asp@CdS QDs smaller than $2 \mathrm{~nm}$. As can be observed from the AFM images (Figure 1c) and the height distribution histograms (Figure 1d) of L-Asp@CdS QDs, the surface of sample is very uniform, with height of $1.63 \pm 0.28 \mathrm{~nm}$, which is consistent with the result of the TEM.

XRD and Raman were used to analyze the compositions and crystalline structures of the obtained product. The XRD patterns (Figure $2 \mathrm{a}$ ) indicate that the peaks at $2 \theta=27.3^{\circ}, 45.1^{\circ}$ and $48.2^{\circ}$ correspond to (002), (110) and (103) plane of hexagonal wurtzite structure (JCPDS No. 41-1049) of CdS, respectively. The HRTEM image of the L-Asp@CdS QDs (Figure 2a, inset) shows the crystalline interplanar spacing was $3.38 \AA$, which aligns with the (002) plane. The Raman spectra further proved the synthesis of CdS. As can be observed in Figure $2 b$, the Raman modes $\left(296 \mathrm{~cm}^{-1}, 596 \mathrm{~cm}^{-1}, 893 \mathrm{~cm}^{-1}\right)$ are agreement with CdS, which are lower than the reported values of bulk CdS [25,26]. This could be construed as the dipole-dipole interactions between L-Asp@CdS QDs caused many normal modes resulting in broadening and shifting of surface phonon peaks due to the L-Asp@CdS QDs aggregations [26]. 


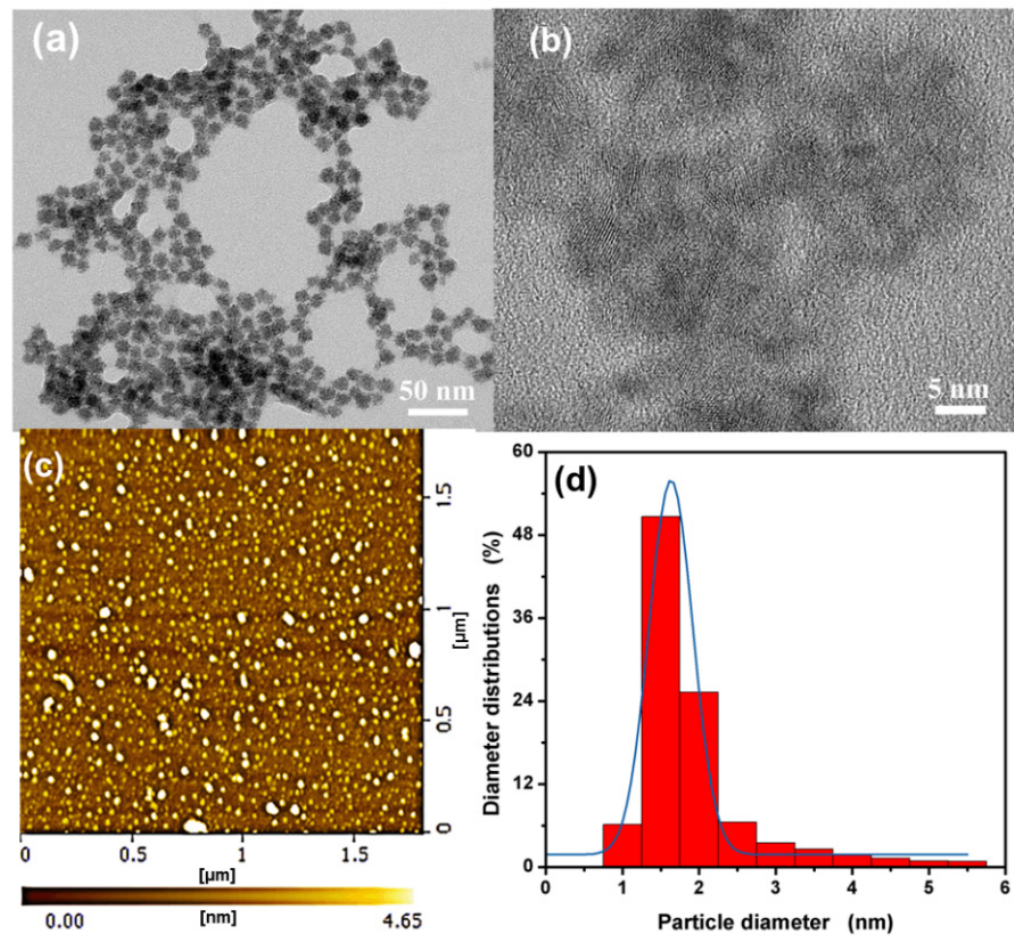

Figure 1. Transmission electron microscopy (TEM) (a), high-resolution TEM (HRTEM) (b,c) atomic force microscope (AFM) images of as-synthesized L-Aspartic acid (L-Asp)@CdS QDs, (d) statistical analysis of the heights of L-Asp@CdS QDs measured by AFM.
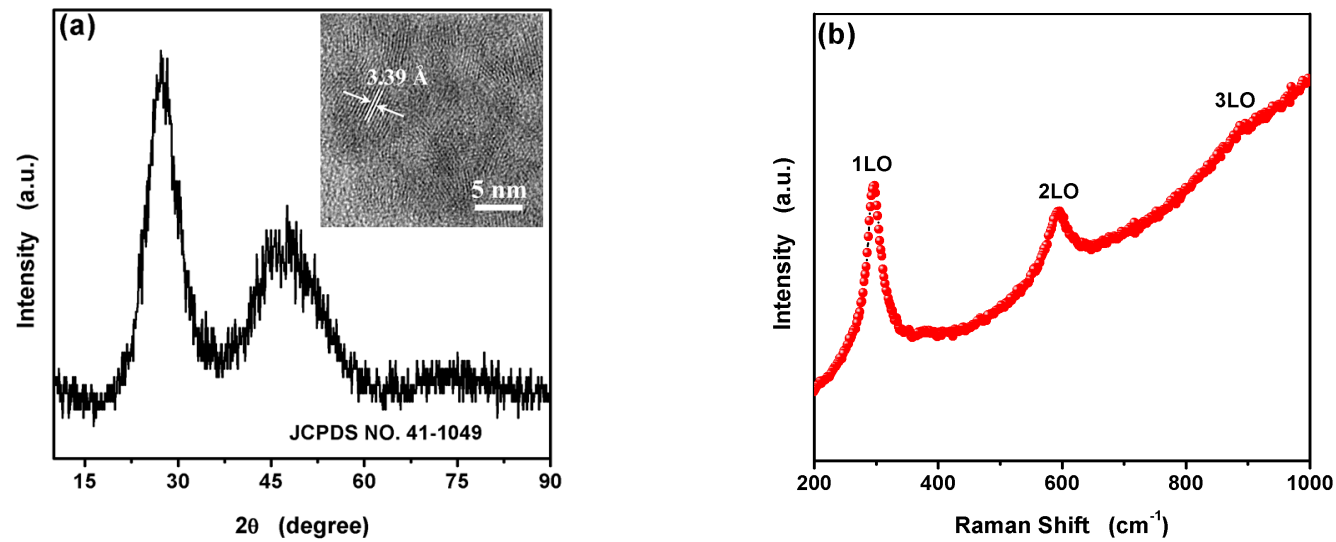

Figure 2. X-ray diffraction pattern (a) and Raman spectra (b) of as-synthesized L-Asp@CdS quantum dots (QDs). The inset of (a) shows the corresponding HRTEM image of L-Asp@CdS QDs.

The IR spectra of pure L-Asp and L-Asp@CdS QDs are displayed in Figure 3. The characteristics groups of L-Asp are $-\mathrm{COOH}$ and $-\mathrm{NH}_{2}$. For L-Asp, its spectrum shown the peaks at around $3424 \mathrm{~cm}^{-1}$, $2962 \mathrm{~cm}^{-1}, 2087 \mathrm{~cm}^{-1}, 1692 \mathrm{~cm}^{-1}, 1412 \mathrm{~cm}^{-1}$ and $1148 \mathrm{~cm}^{-1}$ are assigned to the $\mathrm{N}-\mathrm{H}\left(\mathrm{s} v_{\mathrm{N}-\mathrm{H}}\right), \mathrm{O}-\mathrm{H}$ $\left(s v_{\mathrm{O}-\mathrm{H}}\right), \mathrm{C}-\mathrm{H}\left(\mathrm{s} v_{\mathrm{C}-\mathrm{H}}\right), \mathrm{C}=\mathrm{O}\left(\mathrm{s} v_{\mathrm{C}=\mathrm{O}}\right), \mathrm{COO}-\left(\mathrm{m} v_{\mathrm{COOH}}\right)$, and $\mathrm{C}-\mathrm{NH}_{2}\left(\mathrm{~m} v_{\mathrm{C}-\mathrm{N}}\right)$ [27-29]. For the FTIR spectrum of the L-Asp-CdS QDs, the feature band of $\mathrm{O}-\mathrm{H}\left(\mathrm{s} v_{\mathrm{O}-\mathrm{H}}\right)$ disappears, the band of $\mathrm{C}=\mathrm{O}\left(\mathrm{s} v_{\mathrm{C}=\mathrm{O}}\right)$ shifts from 1692 to $1577 \mathrm{~cm}^{-1}$ and the band of $\mathrm{C}-\mathrm{NH}_{2}\left(\mathrm{~m} v_{\mathrm{C}-\mathrm{N}}\right)$ shifts from 1148 to $1082 \mathrm{~cm}^{-1}$. As a result, L-Asp successfully decorated on the surface of CdS QDs, which are bonded by carboxyl groups rather than amino group.

To further verify the surface element composition and chemical state, the XPS spectra of L-Asp@CdS QDs was researched as indicated in Figure 4. The Cd and S spectra are displayed in Figure 4a,b, respectively. The $\mathrm{Cd} 3 \mathrm{~d}$ peaks are observed at $411.7 \mathrm{eV}$ and $404.9 \mathrm{eV}$, which can be assigned to $\mathrm{Cd} 3 \mathrm{~d}_{3 / 2}$ and $\mathrm{Cd} 3 \mathrm{~d}_{5 / 2}$. For the peaks of $\mathrm{S}$, located at $161 \mathrm{eV}$ and $162.2 \mathrm{eV}$, belong to $S 2 \mathrm{p}_{3 / 2}$ and $\mathrm{S} 2 \mathrm{p}_{1 / 2}$. The +2 
oxidation state of $\mathrm{Cd}$ and -2 oxidation state of $\mathrm{S}$ confirm the existent of $\mathrm{CdS}$ [30,31]. As displayed in Figure 4c, the C 1s peaks appeared at $284.8 \mathrm{eV}, 286.1 \mathrm{eV}$ and $288.2 \mathrm{eV}$ was attribute to the C-C, $\mathrm{C}-\mathrm{O} / \mathrm{C}-\mathrm{N}$ and $\mathrm{C}=\mathrm{O}$, respectively. The $\mathrm{O} 1 \mathrm{~s}$ XPS spectra (Figure $4 \mathrm{~d}$ ) revealed two peaks located at 531.7 and $532.8 \mathrm{eV}$ which correspond to $\mathrm{C}=\mathrm{O}$ and $\mathrm{O}=\mathrm{C}-\mathrm{OH}$, respectively [32]. The presence of carboxyl groups suggests that L-Asp is not a polydentate ligand. Distinctly, the two carboxylate groups of L-Asp are not attached to the surface with equal strength because one of them relates to zwitterion process and can be better connected with CdS QDs [32,33]. Thus, the results proved that the L-Asp@CdS QDs have been successfully synthesized.

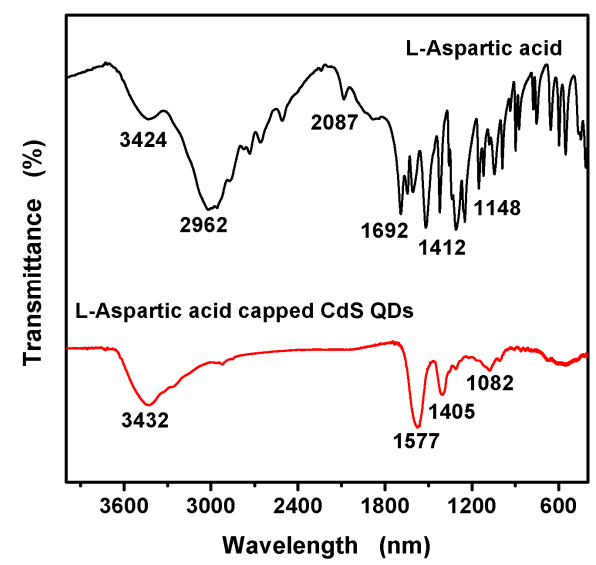

Figure 3. FTIR spectra of L-Asp (black line) and L-Asp@CdS QDs (red line).
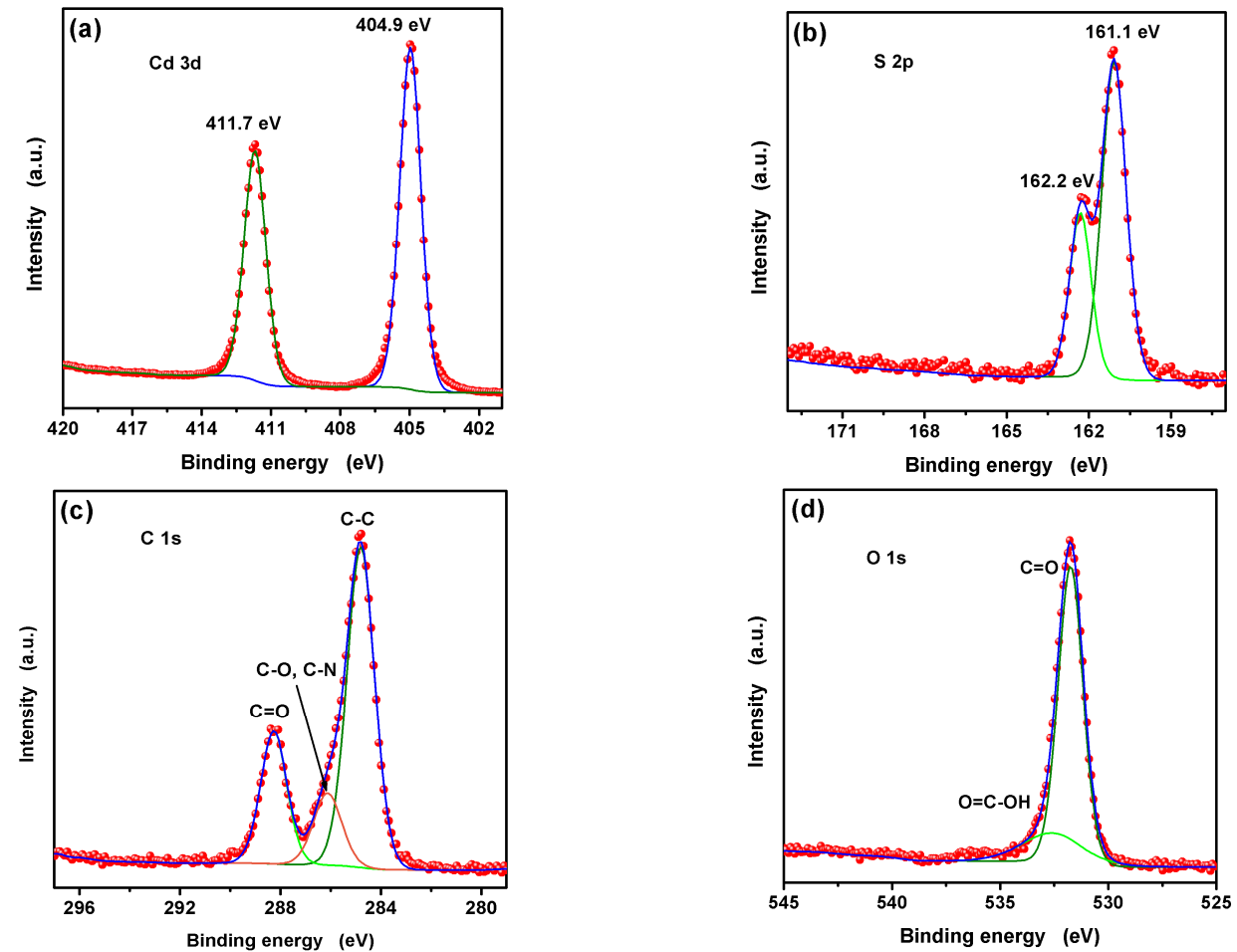

Figure 4. X-ray photoelectron spectroscopy (XPS) spectra of the synthesized L-Asp@CdS QDs: (a) Cd $3 \mathrm{~d}$ spectrum, (b) S 2p spectrum, (c) C 1s and (d) $\mathrm{O}$ 1s spectrum, respectively.

\subsection{Optical Properties of Synthesized L-Asp@CdS QDs}

The UV-vis absorption spectrum and fluorescence spectra were carried for studying the optical properties of L-Asp@CdS QDs. As shown in Figure 5a, the broad absorption band with an absorption edge (the sharply decreasing region of the UV-Vis spectrum of intersecting with the baseline) about 
$459 \mathrm{~nm}$ is obtained. The optical bandgap is estimated to be $2.7 \mathrm{eV}$, which has taken place blue shift contrast with bulk CdS $(2.42 \mathrm{eV})$ due to the quantum confinement of L-Asp@CdS QDs [10]. The maximum emission intensity is observed at $595 \mathrm{~nm}$ and there are two excitation peaks, which are $419 \mathrm{~nm}$ and $376 \mathrm{~nm}$, respectively. The excitation-dependent emission spectra (Figure 5b) show that the emission peak basic remains unchanged under the regulation of excitation wavelength from $385 \mathrm{~nm}$ to $425 \mathrm{~nm}$. When the excitation wavelength is $405 \mathrm{~nm}$, the maximum emission intensity of L-Asp@CdS QDs is obtained. As shown in Figure 5c, CIE coordinates of L-Asp@CdS QDs is located at $(0.485,0.486)$ with a correlated color temperature of $2913 \mathrm{~K}$. The L-Asp@CdS QDs emit orange-yellow light under excitation wavelength of $405 \mathrm{~nm}$. The quantum yield (QY) of the synthetic L-Asp-CdS QDs was calculated to be $9.24 \%$ using rhodamine $6 \mathrm{G}$ as a reference, the low fluorescence quantum yields could be due to the aggregation of L-Asp-CdS QDs.
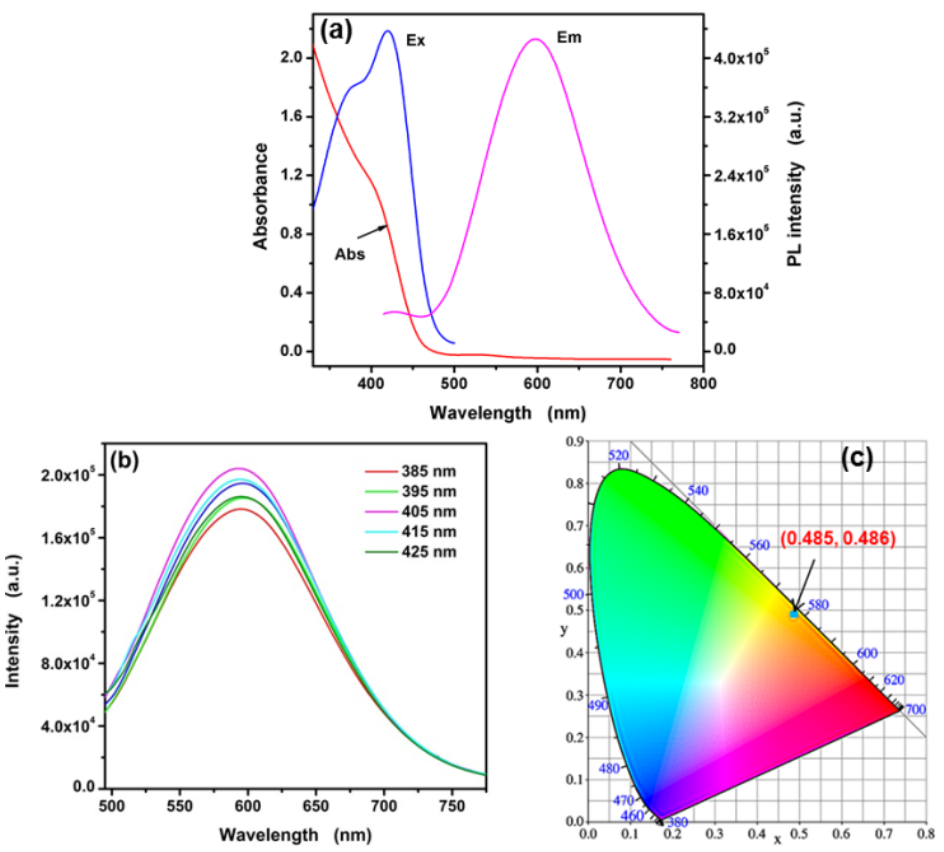

Figure 5. (a) UV-visible absorption (red line), emission spectrum (pink line), excitation spectrum (blue line), and (b) excitation-related emission spectra of L-Asp@CdS QDs, and (c) CIE 1931 coordinates.

\section{3. $\mathrm{Ag}^{+}$Detection Based on the L-Asp@CdS QDs}

In this work, the detection of silver is based on L-Asp@CdS quantum dot fluorescence enhancement. The affecting factors of $\mathrm{pH}$ and concentration were studied in order to obtain the optimal properties to detection $\mathrm{Ag}^{+}$based on the L-Asp@CdS QDs. The results released in Figure S1. As can be discovered, the emission intensity of L-Asp@CdS QDs exhibits the maximum at $\mathrm{pH} 9.0$ with a maximum fluorescence enhancement. Moreover, the maximum emission intensity was obtained when $0.5 \mathrm{~mL}$ L-Asp@CdS QDs was be diluted to $5 \mathrm{~mL}$ simultaneously. It exhibits great relative fluorescence intensity $\left(\mathrm{F} / \mathrm{F}_{0}\right)$ before and after addition of $\mathrm{Ag}^{+}$. Therefore, pH 9.0 and $1.5 \mathrm{~mL}$ L-Asp@CdS QDs was chosen as the optimal condition and applied in the next experiments.

The sensitivity of L-Asp@CdS QDs was investigated based on the change of fluorescence intensity. The fluorescence spectra upon addition of various metal ions are shown in Figure 6a. It is observed that a strong enhancement of fluorescence intensity is observed with the addition of $\mathrm{Ag}^{+}$. Meanwhile, the emission spectra exhibit a red shift. Figure $6 \mathrm{~b}$ depicts the relative fluorescence intensity. As can be seen, there are no obvious fluorescence enhancement when add other metal ions including $\mathrm{Al}^{3+}, \mathrm{Co}^{2+}, \mathrm{Cu}^{2+}$, $\mathrm{Fe}^{2+}, \mathrm{Fe}^{3+}, \mathrm{Hg}^{2+}, \mathrm{Na}^{+}, \mathrm{K}^{+}, \mathrm{La}^{3+}, \mathrm{Li}^{+}, \mathrm{Ni}^{2+}, \mathrm{Pb}^{2+}, \mathrm{Mn}^{2+}, \mathrm{Mg}^{2+}, \mathrm{Cd}^{2+}, \mathrm{Ca}^{2+}$ and $\mathrm{Zn}^{2+}$. To evaluate the resistant to interference of L-Asp@CdS QDs for $\mathrm{Ag}^{+}$detection, the mixtures of $10 \mu \mathrm{M} \mathrm{Ag}^{+}$and $50 \mu \mathrm{M}$ coexisting metal ions were added into L-Asp@CdS QDs solution respectively, then the fluorescence 
enhancement were carried out. Figure $6 \mathrm{c}$ represents that the impact of interfering metal ions is paltry on the fluorescence enhancement. Therefore, the present fluorescence assay system has highly selective and outstanding anti-interference for $\mathrm{Ag}^{+}$detection. Figure 7 a shows a positive correlation between the fluorescence intensity of L-Asp@CdS QDs and the concentration of $\mathrm{Ag}^{+}$. The significant and gradual enhance of the fluorescence intensity is noticed upon addition the varied concentration of $\mathrm{Ag}^{+}$from $100 \mathrm{nM}$ to $10 \mu \mathrm{M}$. As a result, the fluorescence assay system based on L-Asp@CdS QDs is sensitive to the $\mathrm{Ag}^{+}$. Figure $7 \mathrm{~b}$ indicates a good linear relationship between the relative fluorescence intensity and the concentration of $\mathrm{Ag}^{+}$from $100 \mathrm{nM}$ to $7 \mu \mathrm{M}$. The fitting liner equation is $\mathrm{F} / \mathrm{F}_{0}=0.16\left[\mathrm{Ag}^{+}\right]+1.25$ with a fantastic correlation coefficient $\left(\mathrm{R}^{2}\right)$ of 0.9945 . On the basis of this data, the detection limit (LOD) for $\mathrm{Ag}^{+}$was obtained to be $39 \mathrm{~nm}$ based on a signal-to-noise ratio $(\mathrm{S} / \mathrm{N})$ of 3 , which is lower than the limit content in drinking water published by the WHO. The performance comparison of $\mathrm{Ag}^{+}$detection based on several fluorescence assays have been listed in Table 1. As can be seen, the detection limit of the present assay was relatively low with a satisfactory sensitivity.
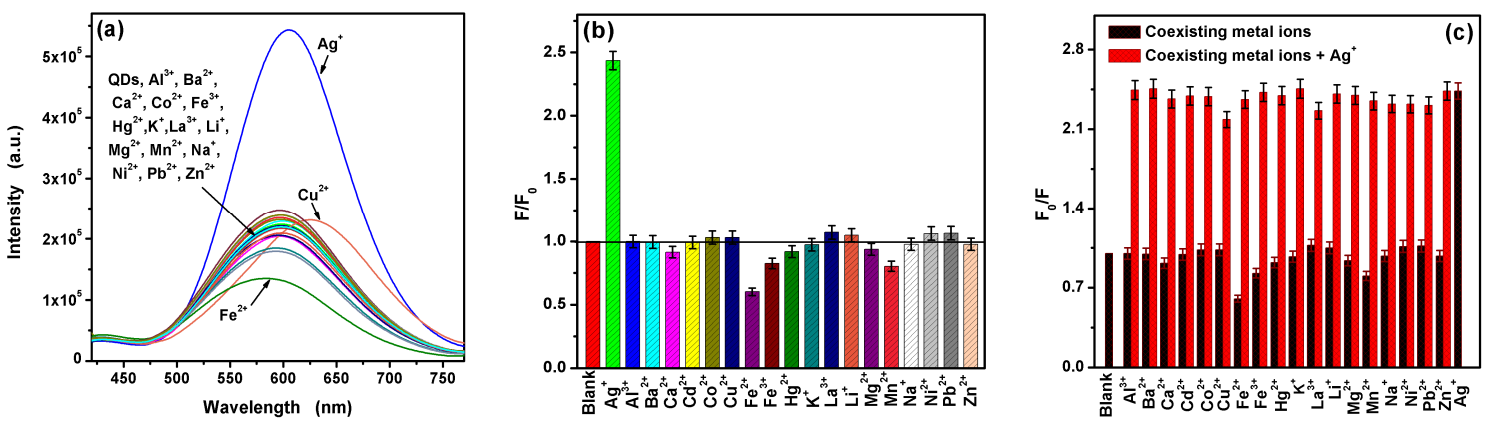

Figure 6. (a) Fluorescence spectra of L-Asp@CdS QDs in the presence of various cations (b) plots of relative fluorescence intensity $\left(\mathrm{F}_{0} / \mathrm{F}\right)$ in the presence of various cations and (c) selective fluorescence response of L-Asp@CdS QDs to $10 \mu \mathrm{M} \mathrm{Ag}^{+}$(wine bars), and interference cations.
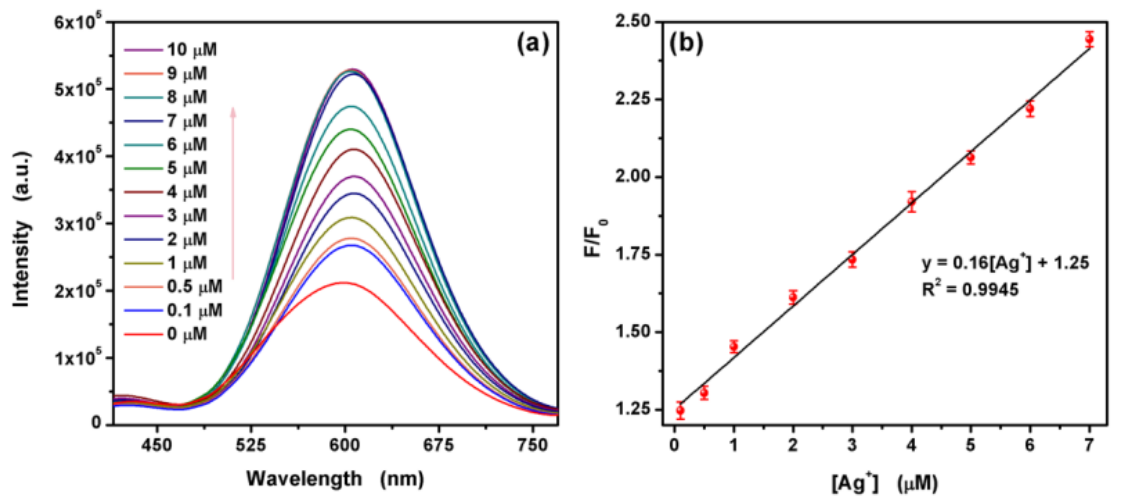

Figure 7. (a) Fluorescence spectra of synthesized L-Asp@CdS QDs solution upon addition of various concentrations of $\mathrm{Ag}^{+},(\mathbf{b})$ relative fluorescence intensity of L-Asp@CdS QDs in the presence of various concentrations of $\mathrm{Ag}^{+}$(the error bar indicates the standard deviation, which was obtained by repeated the experiments 5 times).

Table 1. Comparison the analytical performance of $\mathrm{Ag}^{+}$detection based on fluorescence assay.

\begin{tabular}{cccccc}
\hline Fluorescent Probe & Detection Mode & Linear Range $(\mu \mathbf{M})$ & Detection Limit $(\mu \mathbf{M})$ & Sensitivity $\left(\mu \mathbf{M}^{-1}\right)$ & Ref. \\
\hline CdTe QDs & a F.Q. & $2-10$ & 0.1 & Not given & 0.01649 \\
GQDs & Ratiometric & $0-115.2$ & 0.25 & 0.0053 & {$[34]$} \\
S-GQDs & a F.Q. & $0.1-130$ & 0.03 & 0.4626 & {$[35]$} \\
GSH@CdTe QDs & b F.E. & $0.02-0.2$ & 0.0013 & 0.05 & $0.1151 / 0.055$ \\
TLA-CdTe QDs & a F.Q. & $0.05-10 / 10-100$ & 0.068 & 74.71 & 0.16 \\
Cys-CdS QDs & b F.E. & $0.1-1.5$ & 0.039 & {$[37]$} \\
L-Asp@CdS QDs & b F.E. & $0.1-7$ & This work \\
\hline
\end{tabular}

${ }^{\mathrm{a}}$ F.Q. Fluorescence quenching, ${ }^{\mathrm{b}}$ F.E. Fluorescence enhancement. 


\section{4. $\mathrm{Ag}^{+}$Detection on Real Water Sample}

To evaluate the practicability of the synthesized L-Asp@CdS QDs for $\mathrm{Ag}^{+}$detection, the fluorescence assay was investigated in real drinking water. The water samples are added with $\mathrm{Ag}^{+}$ to be the certain concentration of $0.1,0.5$ and $1.0 \mu \mathrm{M}$. The results are shown in Table 2, which indicate that the measured concentrations are good agreement with the spiked value. The recoveries of $\mathrm{Ag}^{+}$in real water sample are in the range of $98.6-112 \%$. Moreover, the relative standard deviations (RSD) are below $5 \%$ and illustrate that the fluorescence assay has high accuracy. As a result, the fluorescence assay based on the L-Asp@CdS QDs presents excellent sensitivity and has an enormous potential in environmental applications.

Table 2. Analytical results of drinking water samples.

\begin{tabular}{ccccc}
\hline Samples & Spiked $(\boldsymbol{\mu M})$ & Found $(\boldsymbol{\mu M})$ & Recovery $(\%, \mathbf{n}=\mathbf{5})$ & Relative Standard Deviation $(\mathrm{RSD})(\boldsymbol{\%}, \mathbf{n}=\mathbf{5})$ \\
\hline \multirow{3}{*}{ Drinking water } & 0.500 & 0.493 & 98.6 & 3.6 \\
& 1.000 & 1.121 & 112 & 2.1 \\
& 3.000 & 3.168 & 105 & 2.4 \\
\hline
\end{tabular}

\subsection{Mechanism of $\mathrm{Ag}^{+}$Detection Based on the L-Asp@CdS QDs}

In order to explore the fluorescence enhancement mechanism of L-Asp@CdS QDs by $\mathrm{Ag}^{+}$, the TEM image, XRD, XPS and UV-vis spectra of L-Asp@CdS QDs after adding Ag ${ }^{+}$were carried out. From Figure S2 it can be seen that no new phase can be formed. Therefore, the presence of silver sulfide $\left(\mathrm{Ag}_{2} \mathrm{~S}\right)$ is excluded. As displayed in Figure S3, there was no significant new absorption peak appeared upon addition of $\mathrm{Ag}^{+}$ions, which further evidence that $\mathrm{Ag}^{+}$ions do not react with L-Asp@CdS QDs to form $\mathrm{Ag}_{2} \mathrm{~S}$. The XPS information is confirmed the $\mathrm{Ag}^{+}$ions are adsorbed onto the L-Asp@CdS QDs surface. Here, the spectra of survey, Cd 3d, S 2p, Ag 3d, C 1s and O 1s are shown in Figure S4. The appearance of $\mathrm{Ag} 3 \mathrm{~d}$ peaks at $373.7 \mathrm{eV}$ and $367.7 \mathrm{eV}$ respectively corresponding to $\mathrm{Ag} 3 \mathrm{~d}_{3 / 2}$ and

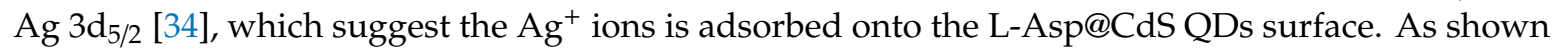
in Figure S5, the TEM image of after addition of $\mathrm{Ag}^{+}$ions shows a better dispersion compared with before the addition of $\mathrm{Ag}^{+}$ions. Therefore, the mechanism of fluorescence enhancement by $\mathrm{Ag}^{+} \mathrm{can}$ be speculated and expressed at Figure 8. The fluorescence of the L-Asp@CdS quantum dots in the aggregation state is weak, which is attributed to the aggregation caused quenching (ACQ) effect [40]. This is owing to the intermolecular $\pi-\pi / n-\pi^{*}$ interactions or other non-radiative channels, which in turn quench its emission [41]. After addition of $\mathrm{Ag}^{+}, \mathrm{Ag}^{+}$adsorbed on the L-Asp@CdS QDs surface and generated electrostatic repulsion. Thus, the L-Asp@CdS QDs dispersion was improved and the ACQ effects were weakened. As a result, $\mathrm{Ag}^{+}$ions adsorbing on the surface of L-Asp@CdS QDs can reduce the non-radiative electron/hole recombination process and then result in fluorescence enhancement.

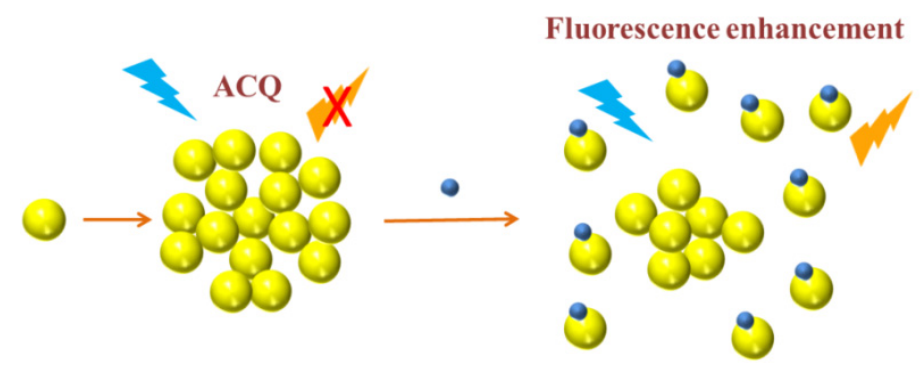

\section{L-Asp@CdS QDs}

- $\mathbf{A g}^{+}$ions

Figure 8. Schematic diagram for L-Asp@CdS QDs fluorescence enhancement by $\mathrm{Ag}^{+}$ions. 


\section{Conclusions}

In summary, the hydrothermal method has been successfully first used in the synthesis of L-aspartic acid stabilized CdS quantum dots. The synthesized L-Asp@CdS QDs show an outstanding selectivity and sensitivity for $\mathrm{Ag}^{+}$ions detection by fluorescence enhancement. As a result, an excellent linear relationship was found in the range of $0.1-7 \mu \mathrm{M}$ with LOD of $0.039 \mu \mathrm{M}$, which is below the minimum level of $\mathrm{Ag}^{+}$ions in drinking water published by the WHO. Moreover, the proposed fluorescence assay has been applied in the real drinking water and a pretty result was obtained. Hence, the present fluorescence assay has a potential application for $\mathrm{Ag}^{+}$detection in environment water sample.

Supplementary Materials: The following are available online at http://www.mdpi.com/2079-4991/9/8/1165/s1, Figure S1: (a) Fluorescence spectra at different volumes of L-Asp@CdS QDs in buffer solution at pH 9 and (b) luorescence intensity without (red) and with (violet) $10 \mu \mathrm{M} \mathrm{Ag}^{+}$, and the relative fluorescence intensity of volume dependence (blue) of L-Asp@CdS QDs, (c) effect of $\mathrm{pH}$ on the fluorescence intensity and (d) fluorescence intensity without (red) and with (violet) $10 \mu \mathrm{M} \mathrm{Ag}^{+}$, and relative fluorescence intensity of $\mathrm{pH}$ dependence (blue)of L-Asp@CdS QDs, Figure S2: XRD patterns of L-Asp@CdS QDs in the absence and presence of Ag ${ }^{+}$ions, Figure S3: UV-vis absorption spectra of L-Asp@CdS QDs in the presence of various concentrations of $\mathrm{Ag}^{+}$ions, inset, the photographs under exposure of white and UV (365 nm) light, Figure S4: XPS spectra of the L-Asp@CdS QDs upon addition of $\mathrm{Ag}^{+}$ions: (a) survey, (b) Cd 3d spectrum, (c) S 2p spectrum, (d) Ag 3d, (e) C 1s and (f) O 1s spectrum, Figure S5: The TEM and HRTEM images of L-Asp@CdS QDs upon addition of $\mathrm{Ag}^{+}$ions, Table S1: The information of Yunnan Spring.

Author Contributions: Z.W. (Zhezhe Wang) synthesized the samples, carried out the PL experiments, and wrote the main manuscript, X.X. (Xuechun Xiao), Y.Y. and T.Z. analyzed the experimental data. X.X. (Xinxin Xing), R.Z. and Z.W. (Zidong Wang) performed the characterization test. Y.W. and X.X. (Xuechun Xiao) revised and edited the paper.

Funding: This work was supported by the Department of Science and Technology of Yunnan Province via the Key Project for the Science and Technology (Grant No.2017FA025), National Natural Science Foundation of China (No. 61761047 and 41876055) and Program for Innovative Research Team (in Science and Technology) in University of Yunnan Province.

Conflicts of Interest: The authors declare no conflicts of interest.

\section{References}

1. Sousa, J.C.L.; Vivas, M.G.; Ferrari, J.L.; Schiavon, M.A. Synthesis and optical properties of water-soluble $\mathrm{CdTe}: \mathrm{Zn}^{2+}$ quantum dots prepared by the one-pot approach. J. Braz. Chem. Soc. 2018, 29, 2496-2501. [CrossRef]

2. Hameau, S.; Guldner, Y.; Verzelen, O.; Ferreira, R.; Bastard, G.; Zeman, J.; Lemaitre, A.; Gerard, J.M. Strong electron-phonon coupling regime in quantum dots: Evidence for everlasting resonant polarons. Phys. Rev. Lett. 1999, 83, 4152-4155. [CrossRef]

3. Chen, J.L.; Zhu, C.Q. Functionalized cadmium sulfide quantum dots as fluorescence probe for silver ion determination. Anal. Chim. Acta 2005, 546, 147-153. [CrossRef]

4. Ramalingam, G.; Saravanan, K.V.; Vizhi, T.K.; Rajkumar, M.; Baskar, K. Synthesis of water-soluble and bio-taggable CdSe@ZnS quantum dots. RSC Adv. 2018, 8, 8516-8527. [CrossRef]

5. Muthalif, M.P.A.; Sunesh, C.D.; Choe, Y. Enhanced light absorption and charge recombination control in quantum dot sensitized solar cells using tin doped cadmium sulfide quantum dots. J. Colloid Interface Sci. 2019, 534, 291-300. [CrossRef] [PubMed]

6. Vu, H.T.; Huang, Y.; Yu, H.C.; Su, Y.K. Ultrathin PVK charge control layer for advanced manipulation of efficient giant CdSe@ZnS/ZnS quantum dot light-emitting diodes. Org. Electron. 2018, 63, 349-354. [CrossRef]

7. Zou, W.S.; Deng, M.Y.; Wang, Y.Q.; Zhao, X.L.; Li, W.H.; Huang, X.H. Alginate capped and manganese doped $\mathrm{ZnS}$ quantum dots as a phosphorescent probe for time-resolved detection of copper(II). Microchim. Acta 2019, 186, 1. [CrossRef]

8. Mohamed, N.B.N.; Brahim, N.; Mrad, R.; Haouari, M.; Ban Chaabane, R.; Negrerie, M. Use of MPA-capped $\mathrm{CdS}$ quantum dots for sensitive detection and quantification of $\mathrm{Co}^{2+}$ ions in aqueous solution. Anal. Chim. Acta 2018, 1028, 50-58. [CrossRef] 
9. Chan, W.C.W.; Maxwell, D.J.; Gao, X.H.; Bailey, R.E.; Han, M.Y.; Ni, S.M. Luminescent quantum dots for multiplexed biological detection and imaging. Curr. Opin. Biotechnol. 2002, 13, 40-46. [CrossRef]

10. Wang, Z.Z.; Xiao, X.C.; Zou, T.; Yang, Y.; Xing, X.X.; Zhao, R.Z.; Wang, Z.D.; Wang, Y.D. Citric acid capped CdS quantum dots for fluorescence detection of copper ions (II) in aqueous solution. Nanomaterials 2019, 9 , 32. [CrossRef]

11. Xu, X.; Long, Y.W.; Pan, S.; Liu, H.; Yang, J.D.; Hu, X.L. S-doped carbon dots capped ZnCdTe quantum dots for ratiometric fluorescence sensing of guanine. Sens. Actuators B Chem. 2019, 279, 44-52. [CrossRef]

12. Ngamdee, K.; Ngeontae, W. Circular dichroism glucose biosensor based on chiral cadmium sulfide quantum dots. Sens. Actuators B Chem. 2018, 274, 402-411. [CrossRef]

13. Pourghbadi, Z; Mirahmadpour, P.; Zare, H. Fluorescent biosensor for the selective determination of dopamine by TGA-capped CdTe quantum dots in human plasma samples. Opt. Mater. 2018, 84, 757-762. [CrossRef]

14. Sianglam, P.; Kulchat, S.; Tuntulani, T.; Ngeontae, W. A circular dichroism sensor for selective detection of $\mathrm{Cd}^{2+}$ and $\mathrm{S}^{2-}$ based on the in-situ generation of chiral CdS quantum dots. Spectrochim. Acta Part A Mol. Biomol. Spectrosc. 2017, 183, 408-416. [CrossRef]

15. Park, J.; Choi, W.; Jang, K.; Na, S. High-sensitivity detection of silver ions using oligonucleotide-immobilized oscillator. Biosens. Bioelectron. 2013, 41, 471-476. [CrossRef]

16. Xu, J.Y.; Zhang, H.Q. Long-term effects of silver nanoparticles on the abundance and activity of soil microbiome. J. Environ. Sci. 2018, 69, 3-4. [CrossRef]

17. Tang, H.Q.; Feng, H.J.; Zhang, J.H.; Zhao, J. A study on antibacterial properties of $\mathrm{Ag}^{+}$-implanted pyrolytic carbon. Surf. Coat. Technol. 2007, 201, 5633-5636. [CrossRef]

18. Chun, K.Y.; Oh, Y.; Rho, J.; Ahu, J.H.; Kim, Y.J.; Choi, H.R.; Baik, S. Highly conductive, printable and stretchable composite films of carbon nanotubes and silver. Nat. Nanotechnol. 2010, 5, 853-857. [CrossRef]

19. Feng, D.Q.; Liu, G.; Zheng, W.; Liu, J.; Chen, T.; Li, D. A highly selective and sensitive on-off sensor for silver ions and cysteine by light scattering technique of DNA-functionalized gold nanoparticles. Chem. Commun. 2011, 47, 8557-8559. [CrossRef]

20. Haghnazari, N.; Alizadeh, A.; Karami, C.; Hamidi, Z. Simple optical determination of silver ion in aqueous solutions using benzo crown-ether modified gold nanoparticles. Microchim. Acta 2013, 180, 287-294. [CrossRef]

21. World Health Organization. World Health Organization's Guidelines for Drinking-water Quality, 4th ed.; World Health Organization: Geneva, Switzerland, 2011; p. 564.

22. Frankowski, M.; Ziola-Frankowsha, A.; Siepak, J. New method for speciation analysis of aluminium fluoride complexes by HPLC-FAAS hyphenated technique. Talanta 2010, 80, 2120-2126. [CrossRef]

23. Katarina, P.K.; Takayanagi, T.; Oshima, M.; Motomizu, S. Synthesis of a chitosan-based chelating resin and its application to the selective concentration and ultratrace determination of silver in environmental water samples. Anal. Chim. Acta 2006, 558, 246-253. [CrossRef]

24. Dasbasi, T.; Sacmaci, S.; Sahan, S.; Kartal, S.; Ulgen, A. Synthesis, characterization and application of a new chelating resin for on-line separation, preconcentration and determination of $\mathrm{Ag}(\mathrm{I})$ by flame atomic absorption spectrometry. Talanta 2013, 103, 1-7. [CrossRef]

25. Thambidurai, M.; Muthukumarasamy, N.; Agilan, S.; Arul, N.S.; Murugan, N.; Balasundaraprabhu, R. Structural and optical characterization of Ni-doped CdS quantum dots. J. Mater. Sci. 2011, 46, 3200-3206. [CrossRef]

26. Solanki, R.G.; Rajaram, P.; Bajpai, P.K. Growth, characterization and estimation of lattice strain and size in CdS nanoparticles: X-ray peak profile analysis. Indian J. Phys. 2018, 92, 595-603. [CrossRef]

27. Hosseini, M.S.; Kamali, M. Synthesis and characterization of aspartic acid-capped CdS/ZnS quantum dots in reverse micelles and its application to $\mathrm{Hg}$ (II) determination. J. Lumin. 2015, 167, 51-58. [CrossRef]

28. Heidari-Chaleshtori, M.; Nezamzadeh-Ejhieh, A. Clinoptilolitenano-particles modified with aspartic acid for removal of $\mathrm{Cu}(\mathrm{II})$ from aqueous solutions: Isotherms and kinetic aspects. New J. Chem. 2015, 39, 9396-9406. [CrossRef]

29. Mahapatra, N.; Panja, S.; Mandal, A.; Haider, M. A single source-precursor route for the one-pot synthesis of highly luminescent CdS quantum dots as ultra-sensitive and selective photoluminescence sensor for $\mathrm{Co}^{2+}$ and $\mathrm{Ni}^{2+}$ ions. J. Mater. Chem. C 2015, 2, 7373-7384. [CrossRef] 
30. Krishnakumar, V.; Ranjith, R.; Jayaprakash, J.; Boobas, S.; Venkatesan, J. Enhancement of photocatalytic degradation of methylene blue under visible light using transparent Mg-doped CdS-PVA nanocomposite films. J. Mater. Sci. Mater. Electron. 2017, 28, 13990-13999. [CrossRef]

31. Gopannagari, M.; Kumar, D.P.; Park, H.; Kim, E.H.; Bhavani, P.; Reddy, D.A. Influence of surface-functionalized multi-walled carbon nanotubes on CdS nanohybrids for effective photocatalytic hydrogen production. Appl. Catal. B Environ. 2018, 236, 294-303. [CrossRef]

32. Yang, Y.; Xiao, X.C.; Xing, X.X.; Wang, Z.Z.; Zou, T.; Wang, Z.D.; Zhao, R.Z.; Wang, Y.D. Rhodamine B assisted graphene quantum dots fluorescent sensor system for sensitive recognition of mercury ions. J. Lumin. 2019, 207, 273-281. [CrossRef]

33. Wang, R.Y.; Fan, H.L.; Jing, W.; Ni, G.S.; Qu, S.J. Amino-functionalized graphene quantum dots prepared using high-softening point asphalt and their application in $\mathrm{Fe}^{3+}$ detection. Appl. Surf. Sci. 2019, 467, 446-455. [CrossRef]

34. Sun, W.L.; Yao, J.L.; Yao, T.M.; Shi, S. Label-free fluorescent DNA sensor for the detection of silver ions based on molecular light switch Ru complex and unmodified quantum dots. Analyst 2013, 138, 421-424. [CrossRef]

35. Zhao, X.E.; Lei, C.H.; Gao, Y.; Gao, H.; Zhu, S.H.; Yang, X.; Yao, J.M.; Wang, H. A ratiometric fluorescent nanosensor for the detection of silver ions using graphene quantum dots. Sens. Actuators B Chem. 2017, 253, 239-246. [CrossRef]

36. Bian, S.Y.; Shen, C.; Qian, Y.T.; Liu, J.Y.; Xi, F.N.; Dong, X.P. Facile synthesis of sulfur-doped graphene quantum dots as fluorescent sensing probes for $\mathrm{Ag}^{+}$ions detection. Sens. Actuators B Chem. 2017, 242, 231-237. [CrossRef]

37. Wang, H.L.; Zhu, W.J.; Fang, M.; Xu, Y.; Li, C. Turn-on fluorescence probe for high sensitive and selective detection of $\mathrm{Ag}^{+}$by L-glutathione capped CdTe quantum dots in aqueous medium. J. Lumin. 2016, 180, 14-19. [CrossRef]

38. Mahapatra, N.; Mandal, A.; Panja, S.; Haider, M. Emergence of the selective ultra-sensing of Ag(I): Thiolactic acid as efficient capping agent for cadmium chalcogenide quantum dots in modulating photoluminescence and metal reception. Sens. Actuators B Chem. 2017, 240, 543-552. [CrossRef]

39. Khantaw, T.; Boonmee, C.; Tuntulani, T.; Ngeontae, W. Selective turn-on fluorescence sensor for $\mathrm{Ag}^{+}$using cysteamine capped CdS quantumdots: Determination of free $\mathrm{Ag}^{+}$in silver nanoparticles solution. Talanta 2013, 115, 849-856. [CrossRef]

40. Jenekhe, S.A.; Osaheni, J.A. Excimers and exciplexes of conjugated polym. Science 1994, 265, 765-768. [CrossRef]

41. Nie, H.; Hu, K.; Cai, Y.J.; Peng, Q.; Zhao, Z.J.; Hu, R.R.; Chen, J.W.; Su, S.J.; Qin, A.J.; Tang, B.Z. Tetraphenylfuran: Aggregation-induced emission or aggregation caused quenching? Mater. Chem. Front. 2017, 1, 1125-1129. [CrossRef]

(C) 2019 by the authors. Licensee MDPI, Basel, Switzerland. This article is an open access article distributed under the terms and conditions of the Creative Commons Attribution (CC BY) license (http://creativecommons.org/licenses/by/4.0/). 